\title{
Expression of Cyr61 is associated with clinical course in patients with Crohn's disease
}

\author{
Su-Mi Lee ${ }^{1 \dagger}$, Kyung-Hwa Lee ${ }^{2 \dagger}$, Seon-Young Park ${ }^{1 * \dagger}$, Dong Hyun Kim ${ }^{1}$, Jin Ook Chung ${ }^{1}$, Jae Kyun Ju ${ }^{3}$,
} Jae-Hyuk Lee ${ }^{2}$ and Hyun Soo Kim ${ }^{1 *+}$

\begin{abstract}
Backgrounds: Cysteine-rich angiogenic inducer 61 (Cyr61) is emerging as an important regulator of tissue homeostasis and wound repair. We aim to explore the colonic mucosal expression of Cyr61 and analyze the association between Cyr61 expression and clinical course in patients with Crohn's disease (CD).

Methods: Endoscopic samples were identified from 83 CD patients with and 372 controls by searching pathological reports. Among them, age- and sex- matched 43 of each group by a propensity score were selected to compare Cyr61 expression by immunohistochemistry (IHC). IHC scores for Cyr61 expression of CD patients were divided into tertiles to evaluate the association with clinical course. We also measured the level of mRNA for Cyr 61 and proinflammatory genes in inflamed and noninflamed colonic mucosal lesions from CD patients.

Results: The mean IHC scores for Cyr61 expression was higher in CD patients (86.5) than in controls $(46.1, P<0.001)$. In CD patients, the mean IHC scores for Cyr61 expression (68.3) was lower in patients with clinical recurrence than in patients without recurrence $(92.2, P=0.01)$. Cyr61 mRNA levels in inflamed mucosa were twofold higher than those in non-inflamed lesion $(P>0.05)$ and the mRNA levels of IL-6 and TLR-4 in inflamed mucosa were significantly higher than those in non-inflamed mucosa in CD patients (all $P<0.05$ ). When CD patients were stratified into tertile groups according to $\mathrm{HC}$ scores for Cyr61 expression, clinical recurrence rates tended to be lower in patients with high Cyr61 expression ( $P$ for trend $=0.02$ ). Compared with tertile 1 of Cyr61 expression, tertile 3 of Cyr 61 expression was associated with reduced risk of clinical recurrence (OR $0.43,95 \%$ Cl 0.20-0.92) after adjustment for age, sex and CD activity index at the time of colonoscopy in CD patients $(P=0.03)$.
\end{abstract}

Conclusions: Cyr61 mucosal expression in CD patients was inversely associated with clinical course. Future study need to be considered to evaluate whether Cyr 61 may play a role in activating inflammatory responses and contributing to wound healing and tissue repair in patients with CD.

Keywords: Crohn's disease, Cyr61, Inflammation, Recurrence

*Correspondence: drpsy@naver.com; dshskim@jnu.ac.kr; hskim@chonnam. ac.kr

${ }^{\dagger} \mathrm{SM}$ Lee and KH Lee contributed equally to this work as first authors

${ }^{\dagger}$ SY Park and HS Kim contributed equally to this work as corresponding authors

${ }^{1}$ Department of Internal Medicine, Chonnam National University Medical School, 42, Jaebongro, Dong-ku, Gwangju 501-757, Korea

Full list of author information is available at the end of the article

\section{Background}

Crohn's disease (CD) is characterized by idiopathic chronic inflammatory damage affecting any portion of the intestinal tract [1]. To preserve normal homeostasis, wound-healing processes following injuries or physiological damage are needed [2], and better understanding of 
these repair mechanisms may aid treatment approaches for damaged intestine in patients with $\mathrm{CD}$.

Cysteine-rich angiogenic inducer 61 (Cyr61, CCN1) is a secreted heparin-binding extracellular matrix-associated protein and is emerging as an important regulator of tissue homeostasis and wound repair through the control of cell adhesion and cell migration [3, 4]. Previous study showed that Cyr 61 levels in the colonic mucosa from patients with inflammatory bowel disease and mice with experimental colitis were increased, suggesting the involvement of Cyr61 in the pathogenesis of a colitis model [5]. Other study demonstrated lower Cyr61 expression in dermal fibroblasts from patients with systemic sclerosis compared to healthy controls [6]. Recently, Lin et al. suggested that serum Cyr61 was associated with inflammatory cytokines and disease activities in patients with rheumatoid arthritis and systemic lupus erythematosus (SLE) [7, 8]. Until now, there is limited information regarding whether Cyr61 plays any role in inflammatory processes or is associated with clinical disease activity and/or clinical course in patients with CD.

In this study, we aim to explore the colonic mucosal expression of Cyr61 in patients with CD and analyze the association between Cyr61 expression and clinical disease activity and/or prognosis.

\section{Methods}

\section{Subjects and samples}

We identified endoscopic biopsy samples from ileocolic lesion of 83 patients with $C D$ and 372 controls by searching pathological report files at Chonnam National University Hospital between Jan 2018 and June 2019. All 372 control group subjects had no significant pathological findings and no clinical history of inflammatory bowel disease or neoplasia. Among $83 \mathrm{CD}$ patients and 372 controls, 43 of each group were selected through propensity score matching to reduce the effects of age and sex.

\section{Histopathologic assessment of inflammatory activities and immunohistochemistry of Cyr61}

To evaluate the histopathologic assessment of inflammatory activities of biopsy specimens in patients with $\mathrm{CD}$, we used the pathologic scoring system suggested by Naini et al. [9] including ileitis score $(0-10)$ and colitis score (0-17).

Cyr61 protein expression in mucosal tissues was evaluated by immunohistochemistry (IHC). Briefly, formalin-fixed paraffin-embedded (FFPE) blocks were cut at $3-\mu \mathrm{m}$ thickness and immunostained with a specific antibody against Cyr61 protein (1:1500 dilution; catalog no. ab10760; Abcam, Cambridge, UK) using an automated immunostainer (Bond-maX DC2002; Leica Biosystems, Bannockburn, IL, USA). For antigen retrieval, programmed heat-induced epitope retrieval was carried out using bond epitope retrieval solution 1 (containing citrate buffer at $\mathrm{pH}$ 6.0) for $15 \mathrm{~min}$. IHC slides were assessed by two experienced pathologists (JHL and $\mathrm{KHL}$ ), who were blinded to the clinical details. Immunohistochemical staining was re-evaluated for cases showing disagreement between observers. Two pathologists reviewed the cases together and then reached an agreement for inconclusive samples.

The intensity of cytoplasmic immunoreactivity was initially classified into four grades: no staining, weak positivity, moderate positivity, and strong positivity. No cases were completely immunonegative for Cyr61. Cases with weak staining intensity were categorized as 'low-expression' and those with moderate or strong staining intensity were considered as 'high-expression'. The proportion of the stained area was estimated by the ratio of positively stained area over the whole area and expressed as a percentage. IHC scores for Cyr61 expression were calculated by multiplying the intensity grade scale by the stained area percentage [10].

Microscopy images were acquired on a Nikon Eclipse 80i microscope with Plan Fluor objective lenses (DIC $\mathrm{M} / \mathrm{N} 1 \times 10$ and DIC M/N2 $\times 40$ ) using a Nikon DS-Ri2 camera and imaging software NIS-Elements F Ver4.30.01 (Nikon corporation, Tokyo, Japan). The original images were taken with both Fast (Focus) and Quality (Capture) settings set to $3 \times 8$ bit $1636 \times 1088$ and then transformed from combination of width $57.71 \mathrm{~cm}$, height $38.38 \mathrm{~cm}$ and resolution 72 dpi to that of width $6.0 \mathrm{~cm}$, height $4.0 \mathrm{~cm}$ and resolution $600 \mathrm{dpi}$ using Adobe Photoshop version 22.1.1 (Adobe, San Jose, CA, USA).

\section{RNA isolation and real-time polymerase chain reaction of pro-inflammatory genes and Cyr61}

In our previous study, we compared the mRNA levels of proinflammatory genes in the colonic paired mucosal biopsy specimens (inflamed and noninflamed lesions) from each 32 patient with CD [11]. In this study, we used the RNA remaining from those samples to evaluate the degree of inflammation and Cyr61 expression in paired samples from each patient. As we did not have enough amount of RNA in 21 patients, we could analyze the mRNA levels from only 11 patients with CD. Total RNA was extracted using Trizol (Takara, Tokyo, Japan). Briefly, $1 \mathrm{~mL}$ of Trizol solution was added into each well, and then the suspension was collected into a $1.5 \mathrm{~mL}$ tube. After adding $200 \mu \mathrm{L}$ of chloroform (Sigma-Aldrich, St. Louis, MO, USA) and vortexing for 15 secs, the mixture was centrifuged at $20,000 \times g$ for $20 \mathrm{~min}$. The supernatant was then collected and mixed with equal amounts of isopropyl alcohol (MERCK, Kenilworth, NJ, USA) followed by centrifugation at $20,000 \times g \mathrm{rpm}$ for $20 \mathrm{~min}$. The pellet 
was washed with $1 \mathrm{~mL}$ of $70 \%$ ethyl alcohol (MERCK) and centrifuged at $20,000 \times g$ for $5 \mathrm{~min}$. After removing the remaining ethyl alcohol, the RNA pellet was air dried at room temperature and then suspended in $50 \mu \mathrm{L}$ of diethyl pyrocarbonate water.

\section{Outcomes}

We retrieved the clinical disease activities score such as Crohn's disease activity index (CDAI), which was calculated and written on the chart by colonoscopists (KHS and $\mathrm{KDH}$ ) from the collection of daily status for past 7 days around the time of colonoscopy. We also retrieved endoscopic disease activities scores such as simple endoscopic score of Crohn's disease (SES-CD) scale and Crohn's disease endoscopic index of severity (CDEIS) from the medical records, which were calculated by experienced colonoscopists (KHS and $\mathrm{KDH}$ ) around the time of colonoscopy.

We also reviewed the clinical course of patients in medical records after acquiring biopsy specimens. We defined clinical recurrence as a change in prescription, bowel resection, fistulotomy, strictureplasty, stoma formation, CD-related hospitalization, or flare during the follow-up period [11]. CD-related hospitalization was defined as hospitalization because of complications including the following: CD-related surgery, hospitalization for nonsurgical CD-related events such as CD-related flares, hospitalization related to complications/extraintestinal manifestation of $C D$, and disease flare.

\section{Statistical analysis}

Results are expressed as mean (standard deviation, SD) or median value (range). Continuous variables in 2 groups were compared using Student's t-test or the Mann-Whitney test. IHC scores for Cyr61 expression in patients with CD were divided into tertiles: 1 st, $<60(n=27)$; 2 nd, $60-80(\mathrm{n}=30)$ and $3 \mathrm{rd}, \geq 80(\mathrm{n}=26)$. We compared the clinical disease activities such as CDAI, SES-CD and CDEIS according to tertiles of IHC score for Cyr 61 expression using Kruskall Wallis test. The association between Cyr61 expression and clinical recurrence was assessed using univariate and multivariable binary logistic regression. Odd ratio (OR) and $P$ value are presented. Tests for trend were performed using the Cyr61 expression tertiles as ordinal variables in the corresponding logistic regression models. All statistical analyses were performed using SPSS 20.0 (SPSS Inc., Chicago, IL, USA). Two-sided $P$ values $<0.05$ were considered statistically significant.

\section{Ethical consideration}

The study protocol was approved by the Ethics Committee of Chonnam National University Hospital (IRB No. CNUH-2020-121) and was conducted according to the Declaration of Helsinki and Good Clinical Practice guidelines.

\section{Results}

Comparison of Cyr61 expression in patients with CD and matched controls

IHC of Cyr61 was performed on FFPE tissue blocks obtained from 43 patients with $C D$ and 43 controls matched by propensity score for age and sex. Of 43 controls, two were excluded due to inadequate tissue blocks. Therefore, Cyr61 expression was analyzed in 43 patients with $\mathrm{CD}$ (36 with colonic tissue and 7 with ileal tissue) and 41 controls (all colonic tissue). The mean ages (SD) of patients with CD and controls were 34.8 (12.9) and $35.5(12.2)$ years, respectively $(P=0.797)$. There were 31 men in both the patients with $C D$ and control groups $(P>0.999)$. In patients with $C D$, mean inflammatory histologic score (SD) was 9.4 (1.7) in 36 colonic tissue and $5.7(1.4)$ in 7 ileal tissue. Figure 1 showed representative images of control group (Fig. 1a, c) and patients with $\mathrm{CD}$ (Fig. 1b, d).

The IHC scores for Cyr61 expression was higher in patients with $\mathrm{CD}(86.5 \pm 45.9)$ than in controls $(46.1 \pm 13.6, P<0.001$, Fig. 2$)$. In detail, the Cyr61 staining area of patients with $\mathrm{CD}(48.3 \% \pm 21.8 \%)$ was larger than that of controls $(25.6 \% \pm 13.6 \%, P<0.001)$, while there was no significant difference in 'high expression' of Cyr 61 between patients with CD (34/43, 79.0\%) and controls $(32 / 41,78.0 \%, P>0.999)$.

\section{Expression of Cyr61 and pro-inflammatory genes and between inflamed and noninflamed mucosa in patients with $C D$}

To verify the degree of inflammation between the inflamed and noninflamed mucosa, we evaluated the mRNA levels of inflammatory genes. The mRNA levels of IL-6 $(P=0.006)$ and TLR-4 $(P=0.003)$ in inflamed mucosa were significantly higher than those in non-inflamed mucosa. Cyr61 mRNA levels were twofold higher, without significance, than those in noninflamed mucosa ( $P=0.096$, Fig. 3$)$.

\section{Association between IHC expression of Cyr61 and disease activity in patient with $\mathrm{CD}$}

Clinical characteristics of 83 patients with $C D$ are shown in Table 1 . There were 62 men (74.7\%), and the mean age $\pm S D$ was $30.5 \pm 10.7$ years. The median values (range) of CDAI, SES-CD, and CDEIS were 106 $(2-470), 4(0.25-31.5)$, and $5.0(1-36)$, respectively. There were no differences of CDAI $(P=0.620)$, SES-CD 


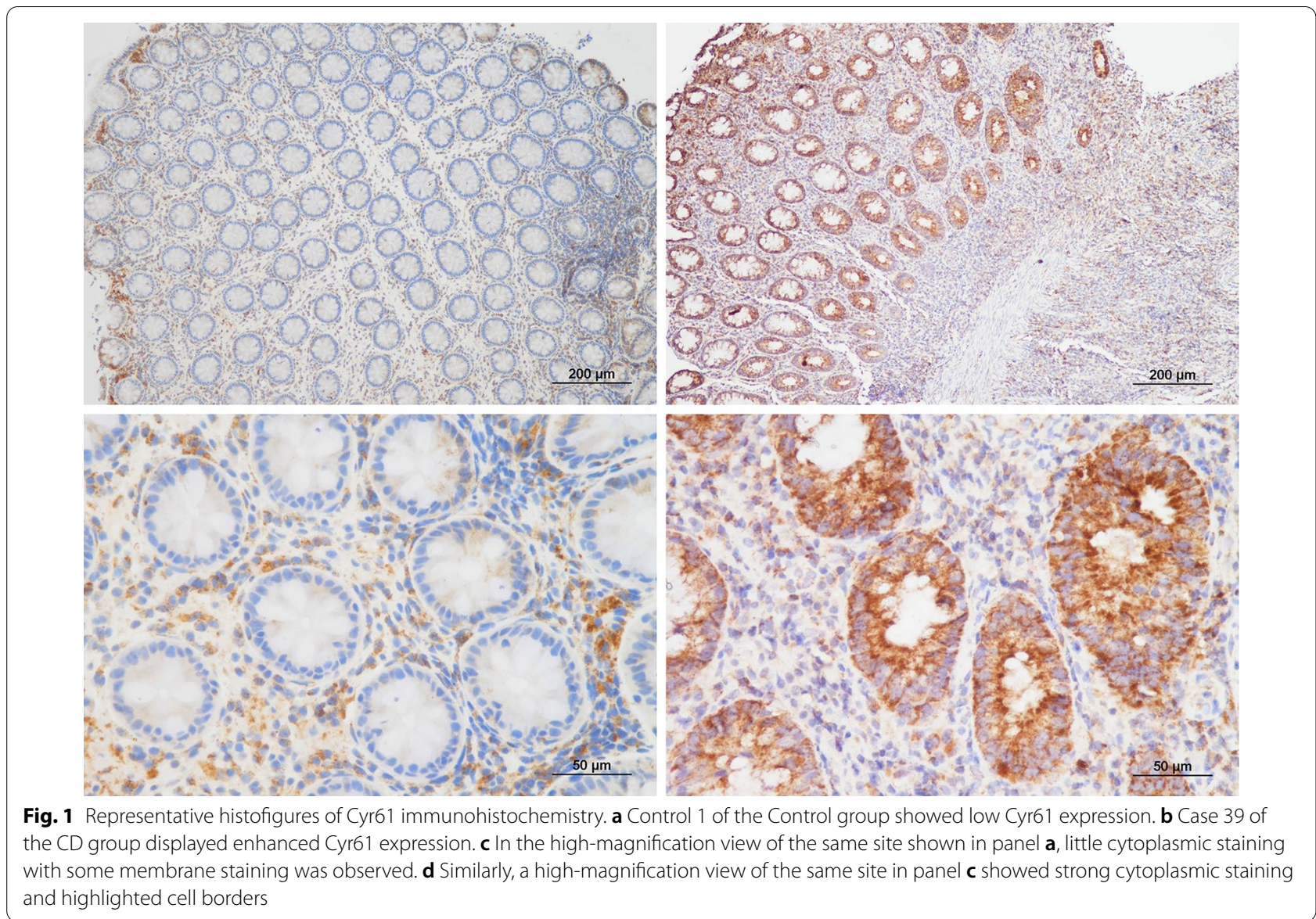

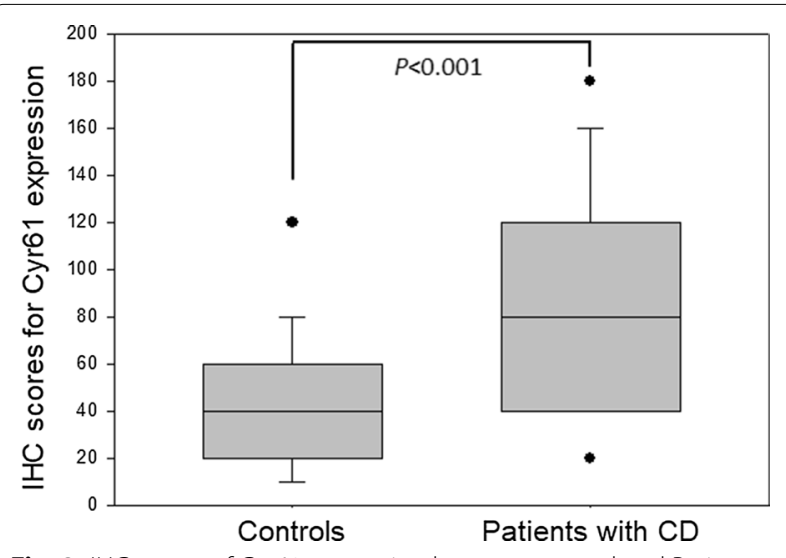

Fig. $2 \mathrm{IHC}$ scores of Cyr61 expression between control and Patients with CD. The Mean IHC scores for Cyr61 expression was higher in patients with CD (86.5) than in controls $(46.1, P<0.001)$. The upper and lower whiskers indicate the 90th and 10th percentiles

$(P=0.482)$ and CDEIS $(P=0.401)$ according to tertiles of IHC scores for Cyr61 expression.

\section{Association between IHC expression of Cyr61 and clinical course in patient with $C D$}

Among 83 patients with CD, 29 (34.9\%) had clinical recurrence during the follow-up period (median 19 months, range 11-26 months). There were 13 patients with a change in prescription, 2 with bowel resection, 6 with fistulotomy, 1 with strictureplasty, 1 with bowel resection and stoma formation, and 15 with CD-related hospitalization. There were no differences in age, sex, disease duration, locations of involvement, medication at the time of colonoscopy between patients with clinical recurrence and patients without clinical recurrences (Table 1, all $P>0.05$ ). Median CDAI score in patients with clinical recurrence (171) was higher than that in patients without clinical recurrence $(100, P<0.01)$.

The IHC scores for Cyr61 expression was lower in patients with clinical recurrence $(68.3 \pm 34.9)$ than in patients without clinical recurrence (92.2 \pm 49.3 , $P=0.01)$. When the patients with $C D$ were stratified into tertile groups according to IHC scores for Cyr61 expression, clinical recurrence rates tended to be lower in patients with high IHC scores for Cyr61 expression $(P$ for trend $=0.02$, Fig. 4). The ORs for clinical recurrences 


\section{CYR-61}

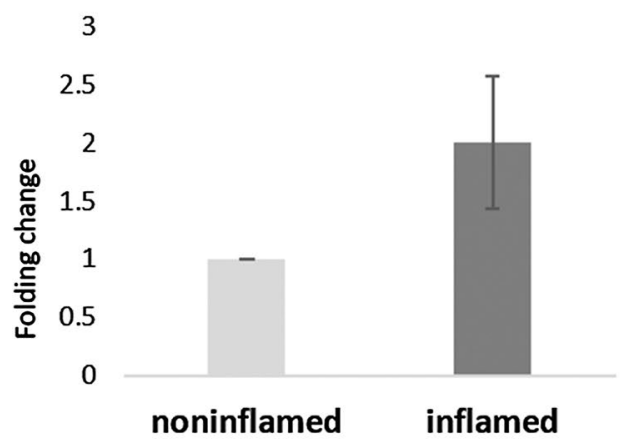

TLR4

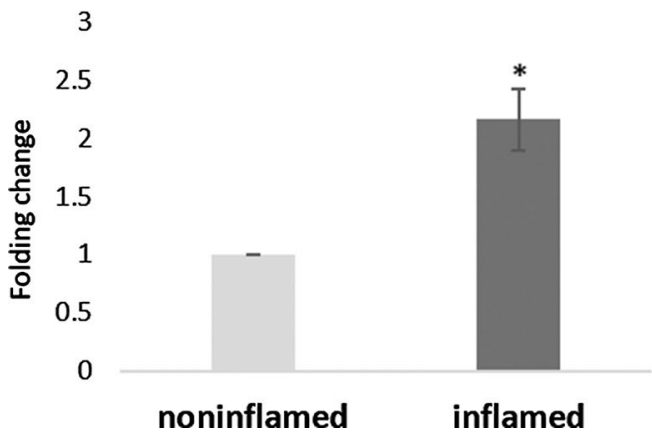

TNF- $\alpha$

2.5

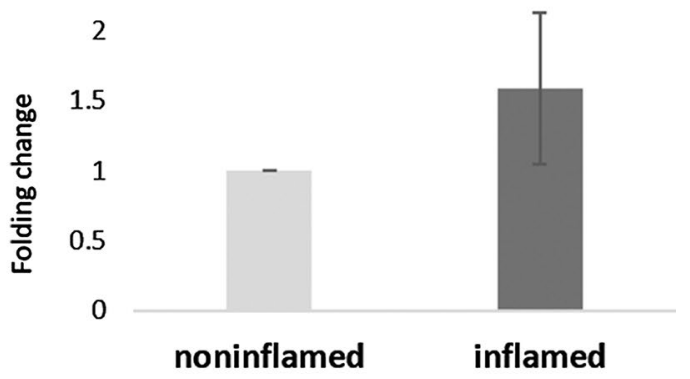

IL-6

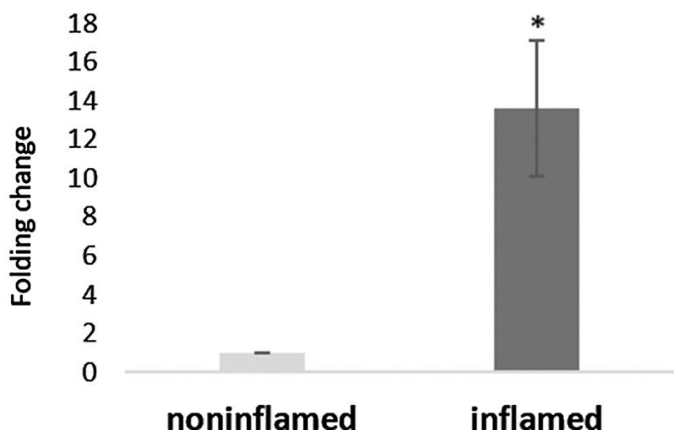

Fig. 3 Expression of Cyr61 and pro-inflammatory genes between inflamed and noninflamed mucosa in patients with Crohn's disease. The mRNA levels of IL- $6^{*}(P<0.01)$ and TLR- $4^{*}(P<0.01)$ in inflamed mucosa were significantly higher than those in non-inflamed mucosa. The mRNA levels of Cyr61 in inflamed mucosa was twofold higher than those in non-inflamed mucosa $(P=0.10)$

Table 1 Baseline characteristics of 83 patients at the time of colonoscopy

\begin{tabular}{|c|c|c|c|}
\hline & $\begin{array}{l}\text { Patients without clinical recurrence } \\
(n=54)\end{array}$ & $\begin{array}{l}\text { Patients with clinical recurrence } \\
(n=29)\end{array}$ & $P$ value \\
\hline Age, years., (mean $\pm S D)$ & $31.6 \pm 11.1$ & $28.4 \pm 9.9$ & 0.21 \\
\hline Male, n (\%) & $40(74.1 \%)$ & $22(75.9 \%)$ & 0.86 \\
\hline Disease duration, years, median (range) & $4.0(0.0 \sim 15.0)$ & $3.0(0.0 \sim 12.0)$ & $0.06^{2}$ \\
\hline Location of disease (Montreal classification), n (\%) & & & 0.54 \\
\hline Ileum (L1) & $4(7.4 \%)$ & $2(6.9 \%)$ & \\
\hline Colon (L2) & $2(3.7 \%)$ & $1(3.4 \%)$ & \\
\hline Ileocolon (L3) & $48(88.9 \%)$ & $24(82.8 \%)$ & \\
\hline Concomitant UGI disease (L4) & $0(0.0 \%)$ & $2(6.9 \%)$ & \\
\hline \multicolumn{4}{|l|}{ Medication at the time of colonoscopy, n (\%) } \\
\hline 5-ASA & $42(77.8 \%)$ & $19(65.5 \%)$ & 0.23 \\
\hline Systematic steroid & $0(0.0 \%)$ & $2(6.9 \%)$ & $0.12^{b}$ \\
\hline Azathioprine/6-mercaptopurine & $19(35.2 \%)$ & $5(17.2 \%)$ & 0.09 \\
\hline TNF- $a$ antagonist & $4(7.4 \%)$ & $3(10.3 \%)$ & $0.70^{b}$ \\
\hline CDAI, median (range) & $100(2-328)$ & $171(41-470)$ & $<0.01^{\mathrm{a}}$ \\
\hline CDEIS, median (range) & $4.0(0.25-31.5)$ & $4.0(0.25-31.0)$ & $0.50^{\mathrm{a}}$ \\
\hline SES-CD, median (range) & $5.0(1.0-36.0)$ & $5(1-27)$ & $0.33^{\mathrm{a}}$ \\
\hline
\end{tabular}

SD standard deviation, 5-ASA 5-aminosalicylic acid, CDAU Crohn's disease activity index, CDEIS Crohn's disease index of severity, SES-CD simple endoscopic score for Crohn's disease

a Man-Whitney U test

b Fisher's exact test 


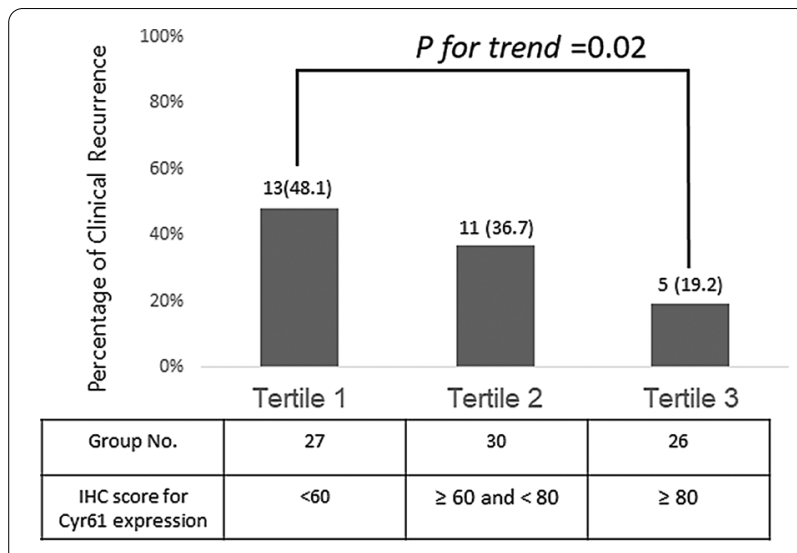

Fig. 4 Clinical recurrence rates according to tertiles of Cyr 61 expression in patients with CD. Data are presented as frequencies (percentages)

according to tertiles of Cyr61 expression are shown in Table 2. Compared with tertile 1 of Cyr61 expression, tertile 3 of Cyr 61 expression was associated with reduced risk of clinical recurrence (OR 0.43, 95\% CI 0.20-0.92) after adjustment for age, sex and CDAI at the time of colonoscopy (Table 2).

\section{Discussion}

In this study, we showed a significant increase in the colonic mucosal expression of Cyr61 in patients with CD compared to that in controls. Colonic mucosal expression of Cyr61 was inversely associated with clinical recurrence in patients with $\mathrm{CD}$.

Several studies showed that the expression of Cyr61 was increased in chronic inflammation models [12-14]; this was also increased in LPS-treated macrophages [12] and in a DSS-induced colitis model, especially during the recovery phase [15]. Su et al. showed that Cyr61 expression was elevated by IL-8 stimulation in gastric cancer cell lines [14]. In skin wound healing and chronic inflammatory liver injuries, Cyr61 played a role in reducing fibrosis during the maturation phase of tissue repair by triggering cellular senescence in activated myofibroblasts
[16-18]. In an experimental model of alcoholic hepatitis, Cyr61 exacerbated apoptosis of hepatocytes [18]. Cyr61 was also known to have angiogenic activity in a model of bone fracture repair [19]. Recent studies reported the involvement of Cyr61 in the pathogenesis of chronic inflammatory diseases such as rheumatoid arthritis $[8$, 20], psoriasis vulgaris [21], Sjogren's syndrome [22], and SLE [7].

In this study, we demonstrated the increased mucosal expression of Cyr61 in patients with CD. To minimize the effects of age and sex on Cyr61 expression, we used propensity score-matching analysis for selection of patients with $\mathrm{CD}$ and controls. The IHC expression of Cyr61 protein in colonic mucosa from patients with $\mathrm{CD}$ was significantly higher than that in colonic mucosa from controls. Previous study suggested that Cyr61 protein expression was observed in only surface epithelial cells of the normal colon, whereas Cyr61 protein expression was observed in the entire mucosal epithelium of DSS-induced colitis mouse models [13]. Likewise, whereas the intensity of Cyr61 expression of patients with CD and controls was not different, the area of Cyr61 expression was higher in patients with $\mathrm{CD}$.

Cyr61 has been known to contribute to inflammatory damage by inducing pro-inflammatory cytokine expression in macrophages and enhancing the cytotoxicity of TNF family cytokines [13, 16, 22]. Cyr61 was associated with upregulated expression of TNF- $\alpha$, IL-6, and IL-17 in patients with SLE [7]. Previous study showed that IL-6 was stimulated by Cyr61, and downregulation of Cyr61 led to reduced IL-6 in fibroblast-like synoviocytes in RA [23]. In this study, we explored the colonic mucosal expression of Cyr61 in inflamed and non-inflamed mucosa from patients with $\mathrm{CD}$. Cyr61 tended to be increased in inflamed mucosa with higher proinflammatory gene expression including IL- 6 and TLR-4.

Cyr61 is also capable of wound healing and tissue repair. Recently, Cyr61 has been reported to opsonize gram negative and gram positive bacteria to accelerate bacterial clearance [24]. Several studies demonstrated that administration of Cyr61 protein accelerated epithelial repair in murine colitis models, human lung

Table 2 Odds ratio for clinical recurrence according to Cyr61 expression tertiles

\begin{tabular}{|c|c|c|c|c|c|c|c|}
\hline \multirow[t]{2}{*}{ Variables } & \multirow{2}{*}{$\begin{array}{l}\text { IHC scores for Cyr61 } \\
\text { expression }\end{array}$} & \multirow[t]{2}{*}{ No. of patients } & \multirow{2}{*}{$\begin{array}{l}\text { Prevalence of clinical } \\
\text { recurrence }\end{array}$} & \multicolumn{2}{|l|}{ Unadjusted } & \multicolumn{2}{|l|}{ Adjusted* } \\
\hline & & & & $\begin{array}{l}\mathrm{OR} \\
(95 \% \mathrm{Cl})\end{array}$ & $P$ value & $\begin{array}{l}\mathrm{OR} \\
(95 \% \mathrm{Cl})\end{array}$ & $P$ value \\
\hline Tertile 1 & $<60$ & 27 & $48.1 \%$ & 1.0 & & 1.0 & \\
\hline Tertile 2 & $\geq 60$ and $<80$ & 30 & $36.7 \%$ & $0.62(0.25-1.80)$ & 0.38 & $0.59(0.18-1.88)$ & 0.37 \\
\hline Tertile 3 & $\geq 80$ & 26 & $19.2 \%$ & $0.26(0.08-0.89)$ & 0.03 & $0.43(0.20-0.92)$ & 0.03 \\
\hline P for trend & & & & 0.03 & & & 0.02 \\
\hline
\end{tabular}

* Adjusted for age, sex and CDAl; OR, odd ratios 
epithelial cells and cutaneous wound [13, 25, 26]. Du et al. showed that upregulation of Cyr61 during the early stage of wound healing and treatment of recombinant human Cyr61 promoted reepithelialization [26]. In line with these finding, it is plausible that variable stress factors may upregulate Cyr61 expression, which may activate inflammatory responses contributing tissue repair in pathomechanism of $\mathrm{CD}$. Therefore, lower Cyr61 expression may be associated with delayed tissue repair leading to worse prognosis. In this present study, we didn't perform the functional experiments about the role of Cyr 61 for tissue repair after inflammation in patients with $C D$. This is the limitation of the current study. Another limitation is that we retrieved the CDAI score, which was calculated and written on the chart by colonoscopist from the collection of daily status for past 7 days. CDAI is the most frequently used index for evaluation of disease activity and the calculation of the CDAI is based on a diary filled in by the patients for 7 days before evaluation [27]. Therefore, we need to perform a well-designed prospective study whether Cyr 61 may play a role in activating inflammatory responses and contributing to wound healing and tissue repair in patients with CD.

\section{Conclusions}

Cyr61 mucosal expression in endoscopic biopsy specimens from patients with $C D$ was inversely associated with clinical course. Future study need to be considered to evaluate whether Cyr 61 may play a role in activating inflammatory responses and contributing to wound healing and tissue repair in patients with $\mathrm{CD}$.

\section{Abbreviations}

Cyr61: Cysteine-rich angiogenic inducer 61; CD: Crohn's disease; IHC: Immunohistochemistry; SLE: Systemic lupus erythematosus; CDAl: Crohn's disease activity index; SES-CD: Simple endoscopic score of Crohn's disease; CDEIS: Crohn's disease endoscopic index of severity.

\section{Acknowledgements}

No.

\section{Authors' contributions}

SYP and HSK, study concept and design; analysis and interpretation of data; drafting and finalizing the manuscript; study supervision; JOC, interpretation of data and drafting and reviewing the manuscript; SML, KHL and JHL conducting the study, collecting and interpreting data, and drafting the manuscript; DHK and JKJ, Analysis of electronic medical records. All authors have read and approved this manuscript.

\section{Funding}

This study was supported by the Chonnam National University Hospital Research Institute of Clinical Medicine (CRI 15005-1 and BCRI-19257) and the National Research Foundation of Korea (NRF) grant funded by the Korea government (2018R1C1B5043483). This funding source had no role in the design of this study and collection, analysis and interpretation of data and in writing the manuscript.

\section{Availability of data and materials}

The datasets generated during and/or analyzed during the current study are available from corresponding author under reasonable request.

\section{Declarations}

Ethics approval and consent to participate

Ethics Committee of the Chonnam National University Hospital approved this current study. (IRB No. CNUH-2020-121). We obtained informed written consent from all participants.

\section{Consent for publication}

Not applicable.

\section{Competing interests}

The authors have no conflicts of interests.

\section{Author details}

${ }^{1}$ Department of Internal Medicine, Chonnam National University Medical School, 42, Jaebongro, Dong-ku, Gwangju 501-757, Korea. ${ }^{2}$ Department of Pathology, Chonnam National University Medical School, Gwangju, South Korea. ${ }^{3}$ Department of General Surgery, Chonnam National University Medical School, Gwangju, South Korea.

Received: 30 June 2020 Accepted: 8 March 2021

Published online: 20 March 2021

\section{References}

1. Baumgart DC, Sandborn WJ. Crohn's disease. Lancet. 2012;380(9853):1590-605

2. Sturm A, Dignass AU. Epithelial restitution and wound healing in inflammatory bowel disease. World J Gastroenterol. 2008;14(3):348-53.

3. Lau LF. CCN1/CYR61: the very model of a modern matricellular protein. Cell Mol Life Sci. 2011;68(19):3149-63.

4. Emre Y, Imhof BA. Matricellular protein CCN1/CYR61: a new player in inflammation and leukocyte trafficking. Semin Immunopathol. 2014;36(2):253-9.

5. Koon HW, Zhao D, Xu H, Bowe C, Moss A, Moyer MP, Pothoulakis C. Substance P-mediated expression of the pro-angiogenic factor CCN1 modulates the course of colitis. Am J Pathol. 2008;173(2):400-10.

6. Tsou PS, Khanna D, Sawalha AH. Identification of cysteine-rich angiogenic inducer 61 as a potential antifibrotic and proangiogenic mediator in scleroderma. Arthritis Rheumatol. 2019;71(8):1350-9.

7. Lin J, Li N, Chen H, Liu C, Yang B, Ou Q. Serum Cyr61 is associated with clinical disease activity and inflammation in patients with systemic lupus erythematosus. Medicine (Baltimore). 2015;94(19):e834.

8. Kwon EJ, Park EJ, Choi S, Kim SR, Cho M, Kim J. PPARgamma agonist rosiglitazone inhibits migration and invasion by downregulating Cyr61 in rheumatoid arthritis fibroblast-like synoviocytes. Int J Rheum Dis. 2017;20(10):1499-509.

9. Naini BV, Cortina G. A histopathologic scoring system as a tool for standardized reporting of chronic (ileo)colitis and independent risk assessment for inflammatory bowel disease. Hum Pathol. 2012;43(12):2187-96.

10. Kho DH, Bae JA, Lee JH, Cho HJ, Cho SH, Lee JH, Seo YW, Ahn KY, Chung IJ, Kim KK. KITENIN recruits Dishevelled/PKC delta to form a functional complex and controls the migration and invasiveness of colorectal cancer cells. Gut. 2009;58(4):509-19.

11. Park SY, Kim JY, Lee SM, Chung JO, Seo JH, Kim S, Kim DH, Park CH, Ju JK, Joo YE, et al. Lower expression of endogenous intestinal alkaline phosphatase may predict worse prognosis in patients with Crohn's disease. BMC Gastroenterol. 2018;18(1):188.

12. Hu T, Chen B, Zhou S, Mao J. Simvastatin inhibits inflammatory response in lipopolysaccharide (LPS)-stimulated RAW264.7 macrophages through the microRNA-22/Cyr61 axis. Int J Clin Exp Pathol 2018, 11(8):3925-3933.

13. Choi JS, Kim KH, Lau LF. The matricellular protein CCN1 promotes mucosal healing in murine colitis through IL-6. Mucosal Immunol. 2015;8(6):1285-96. 
14. Su RL, Qiao Y, Guo RF, Lv YY. Cyr61 overexpression induced by interleukin 8 via NF-kB signaling pathway and its role in tumorigenesis of gastric carcinoma in vitro. Int J Clin Exp Pathol. 2019;12(9):3197-207.

15. Bai T, Chen CC, Lau LF. Matricellular protein CCN1 activates a proinflammatory genetic program in murine macrophages. J Immunol. 2010;184(6):3223-32.

16. Jun Jl, Lau LF. The matricellular protein CCN1 induces fibroblast senescence and restricts fibrosis in cutaneous wound healing. Nat Cell Biol. 2010;12(7):676-85.

17. Kim KH, Chen CC, Monzon Rl, Lau LF. Matricellular protein CCN1 promotes regression of liver fibrosis through induction of cellular senescence in hepatic myofibroblasts. Mol Cell Biol. 2013;33(10):2078-90.

18. Chen CC, Young JL, Monzon RI, Chen N, Todorovic V, Lau LF. Cytotoxicity of TNFalpha is regulated by integrin-mediated matrix signaling. Embo j. 2007;26(5):1257-67.

19. Athanasopoulos AN, Schneider D, Keiper T, Alt V, Pendurthi UR, Liegibel UM, Sommer U, Nawroth PP, Kasperk C, Chavakis T. Vascular endothelial growth factor (VEGF)-induced up-regulation of CCN1 in osteoblasts mediates proangiogenic activities in endothelial cells and promotes fracture healing. J Biol Chem. 2007;282(37):26746-53.

20. Zhang Q, Wu J, Cao Q, Xiao L, Wang L, He D, Ouyang G, Lin J, Shen B, Shi $Y$, et al. A critical role of Cyr61 in interleukin-17-dependent proliferation of fibroblast-like synoviocytes in rheumatoid arthritis. Arthritis Rheum. 2009;60(12):3602-12.

21. Wu P, Ma G, Zhu X, Gu T, Zhang J, Sun Y, Xu H, Huo R, Wang B, Shen B, et al. Cyr61/CCN1 is involved in the pathogenesis of psoriasis vulgaris via promoting IL-8 production by keratinocytes in a JNK/NF-kappaB pathway. Clin Immunol. 2017;174:53-62.
22. Li H, Sun X, Zhang J, Sun Y, Huo R, Li H, Zhai T, Shen B, Zhang M, Li N. Paeoniflorin ameliorates symptoms of experimental Sjogren's syndrome associated with down-regulating Cyr61 expression. Int Immunopharmacol. 2016;30:27-35.

23. Lin J, Zhou Z, Huo R, Xiao L, Ouyang G, Wang L, Sun Y, Shen B, Li D, Li N. Cyr61 induces IL-6 production by fibroblast-like synoviocytes promoting Th17 differentiation in rheumatoid arthritis. J Immunol. 2012;188(11):5776-84.

24. Jun J, Lau LF. CCN1 is an opsonin for bacterial clearance and a direct activator of Toll-like receptor signaling. Nat Commun. 2020;11(1):1242.

25. Zemans RL, McClendon J, Aschner Y, Briones N, Young SK, Lau LF, Kahn M, Downey GP. Role of $\beta$-catenin-regulated CCN matricellular proteins in epithelial repair after inflammatory lung injury. Am J Physiol Lung Cell Mol Physiol. 2013;304(6):L415-427.

26. Du H, Zhou Y, Suo Y, Liang X, Chai B, Duan R, Huang X, Li Q. CCN1 accelerates re-epithelialization by promoting keratinocyte migration and proliferation during cutaneous wound healing. Biochem Biophys Res Commun. 2018:505(4):966-72.

27. Sostegni R, Daperno M, Scaglione N, Lavagna A, Rocca R, Pera A. Review article: Crohn's disease: monitoring disease activity. Aliment Pharmacol Ther. 2003;17(Suppl 2):11-7.

\section{Publisher's Note}

Springer Nature remains neutral with regard to jurisdictional claims in published maps and institutional affiliations.
Ready to submit your research? Choose BMC and benefit from:

- fast, convenient online submission

- thorough peer review by experienced researchers in your field

- rapid publication on acceptance

- support for research data, including large and complex data types

- gold Open Access which fosters wider collaboration and increased citations

- maximum visibility for your research: over 100M website views per year

At BMC, research is always in progress.

Learn more biomedcentral.com/submissions 